\title{
Correction to: Exploring digital support for the student transition to university through questionable concepts
}

\author{
Lisa Thomas ${ }^{1}$ (D) John Vines ${ }^{2} \cdot$ Pam Briggs $^{1}$ \\ Published online: 4 August 2021 \\ (C) Springer-Verlag London Ltd., part of Springer Nature 2021
}

\section{Correction to: Personal and Ubiquitous Computing https://doi.org/10.1007/s00779-021-01570-z}

The authors would like to correct some data found on:

Page 1, the email address of author John Vines should read "john.vines@ed.ac.uk". Affiliation 2 should read "Institute for Design Informatics, University of Edinburgh, Edinburgh, UK".

Page 5, the last sentence of section 3.3 should read "The study was carried out in accordance with the recommendations of Northumbria University Ethics Committee with written informed consent from all participants."

Page 13, author name of reference 38 should read "Dunbar RIM" instead of "RIM D".

\begin{abstract}
Acknowledgements This work was supported by the Engineering and Physical Sciences Research Council, UK (EP/L004062/1). We would like to thank Ben Morrison and Finola Kerrigan for their help as facilitators in our workshops.
\end{abstract}

Data availability statement Due to the sensitive nature of this research, participants did not agree for their data to be shared publicly, so supporting data is not available.

Publisher's note Springer Nature remains neutral with regard to jurisdictional claims in published maps and institutional affiliations.

The online version of the original article can be found at https://oi.org/ 10.1007/s00779-021-01570-Z

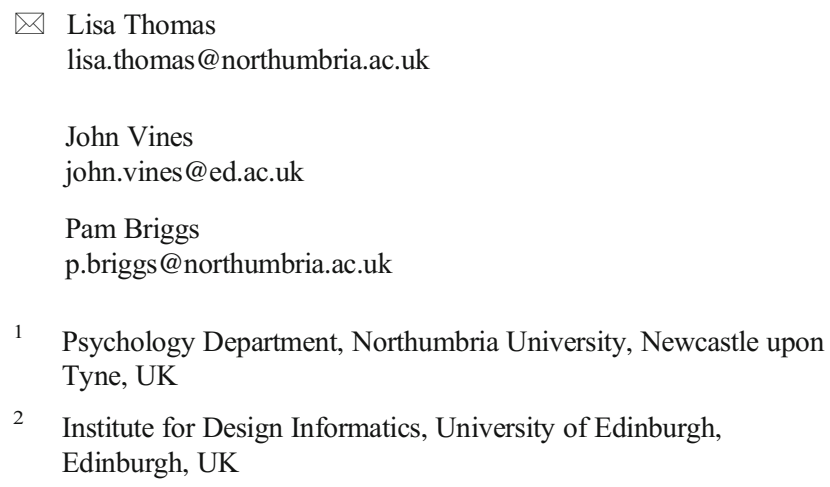

